\title{
La Revuelta de la Vacuna: la lectura iconográfica de la portada de la Revista da Semana (1904)
}

Vaccine Revolt: iconographic reading of the cover of Revista da Semana (1904)

\section{Revolta da Vacina: leitura iconográfica da capa da Revista da Semana (1904)}

\author{
Mercedes $\mathrm{Neto}^{1}$, Francini de Souza Rodrigues ${ }^{2}$, Daniella Cristina \\ Julio Lima², Maria Jorgiane Otaviano de Abrêu², Tiago Braga do \\ Espiríto Santo ${ }^{3}$, Ricardo Mattos Russo Rafael ${ }^{4}$
}

\begin{abstract}
${ }^{1}$ Enfermeira. Doutora em Ciências pelo Programa de Pós-graduação em Enfermagem e Biociências da UNIRIO. Professora adjunta do Departamento de Enfermagem de Saúde Pública da UERJ

${ }^{2}$ Graduandas em enfermagem do 9. ${ }^{\circ}$ período pela Universidade do Estado do Rio de Janeiro

${ }^{3}$ Enfermeiro. Doutor em Enfermagem pelo Programa de Pós-graduação da Escola de Enfermagem da USP.

Professor assistente do Departamento de Enfermagem de Médico Cirúrgico da UERJ

${ }^{4}$ Enfermeiro. Doutor em Ciências pela Universidade do Estado do Rio de Janeiro. Professor adjunto do

Departamento de Enfermagem de Saúde Pública da UERJ
\end{abstract}

Cómo citar este artículo en edición digital: Neto, M., Rodrigues, F. S., Lima, D. C. J., Abrêu, M. J. O., Espirito Santo, T. B. \& Rafael, R. M. R. (2018). La Revuelta de la Vacuna: la lectura iconográfica de la portada de la Revista da Semana (1904). Cultura de los Cuidados (Edición digital), 22(52). Recuperado de http://dx.doi.org/10.14198/cuid.2018.52.06

Correo electrónico: mercedesneto@yahoo.com.br

Telefone: 552128688236-5521992160518

Recibido: 06/03/2018; Aceptado: 23/05/2018

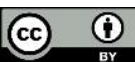

\section{ABSTRACT}

Objective: Analyze the symbolic elements on the cover of the 1904 of Revista da Semana on Vaccine Revolt as a means of imaging a social and sanitary movement.

Method: This is a documental research that has utilized as a subject the preliminary phases of Erwin Panofsky's notions, pre iconographic and iconographic.

Results: The vaccine's uprising portrayed on the cover of the magazine of the week of 1904 shows the imposition of sanitary measures by the government and the popular participation in the struggle against these abusive and vertical proposals with the risk prevention's speech.

Conclusion: With this study it was possible to do a deepening about two characters who are opposite representatives in a society marked by determinants, social disparateness and politics that didn't assist the health and economical reality. And it also portrayed the power relationship in force at the time steps that culminated in the movement of Vaccine Revolt were implemented.

Keywords: Vaccine Revolt, Iconography, Care, Public Health. 


\section{RESUMO}

Objetivo: Analisar os elementos simbólicos na capa da Revista da Semana de 1904 sobre a Revolta da Vacina como meio de leitura imagética de um movimento social e sanitário.

Método: Trata-se de uma pesquisa documental que utilizou como abordagem as primeiras fases de análise das noções de Erwin Panofsky, pré-iconográfica e iconográfica.

Resultados: A Revolta da Vacina retratada na capa da Revista da Semana de outubro de 1904 mostra a imposição do governo de medidas sanitárias e da participação popular na luta contra essas propostas abusivas e verticais com o discurso de prevenção de risco.

Conclusão: Com esse estudo, foi possível fazer um aprofundamento acerca de dois personagens que são representantes opostos dentro de uma sociedade marcada por determinantes, disparidades sociais e com políticas que não favoreciam a realidade econômica e sanitária vivenciada; e também retratava a relação de poder vigente na época em que foram implementadas medidas que culminaram no movimento da Revolta da Vacina.

Palavras chave: Revolta da Vacina, Iconografia, Cuidado, Saúde Pública.

\section{RESUMEN}

Objetivo: Analizar los elementos simbólicos en la portada de la Revista da Semana 1904 en la Revuelta de la Vacuna como medio de lectura de imágenes de un movimiento social y de la salud.

Método: Se trata de una investigación documental que utiliza para acercarse a las primeras etapas del análisis de los conceptos de Erwin Panofsky, pre-iconográfico e iconográfico.
Resultados: La Revuelta de la Vacuna representada en la portada de la revista Semana de Octubre 1904 muestra la imposición por parte del gobierno de las medidas sanitarias y la participación popular en la lucha contra estas propuestas abusivas y verticales con la imposición de la prevención de riesgos.

Conclusión: En este estudio, se realizó un análisis en profundidad alrededor de dos personajes que son representantes opuestos dentro de una sociedad marcada por las desigualdades, y las políticas sociales decisivas que no contemplan la realidad económica y la de la salud como experiencia; y también estableciendo la relación de las tendencias del momento se llevaron a cabo las medidas que dieron como resultado el denominado: "movimiento de la Revuelta de la Vacuna o Rebelión de la Vacuna".

Palabras clave: Vacuna contra la revuelta, Iconografía, cuidado, salud pública.

\section{INTRODUÇÃO}

A primeira vacina foi produzida pelo médico inglês Edward Jenner, em 1796, contra a varíola, doença milenar conhecida no Egito e China antigos, que estava assolando o mundo e dizimando milhares de pessoas. Jenner, após analisar e comprovar uma crença popular, onde se relatava que os camponeses que entravam em contato com as vacas, contraiam uma doença comum que estava presente nas tetas desses animais, proporcionando assim imunidade contra a varíola (Oliveira, 2013).

A partir desta descoberta que houve a primeira inoculação com o vírus da varíola bovina (cow-pox), dando origem ao que conhecemos por vacina, termo que vêm do latim vaccinus, que pela tradução ao português tem o significado de vaca (Oliveira, 2013; Rio de Janeiro, 2006). 
Para contornar a problemática atribuida pelos cientistas da época, foi proposto pelos médicos a vacina humanizada, que consistia em inocular o pus vacínico extraído do animal contaminado e injetar no braço do indivíduo a ser vacinado. Após alguns dias desse procedimento, colhia-se o líquido presente na lesão que fora gerada, e se administrava no braço de outro indivíduo e assim, por diante (Porto; Ângela, Ponte, 2003).

Essa prática dependia que os imunizados retornassem ao posto para que houvesse a coleta do material, porém por ser doloroso e desconfortável, a vacina não obteve uma boa aceitação. O mesmo aconteceu no Brasil, com a chegada desse método em meados do século XIX, dentre os argumentos para a rejeição, entendia-se que por não terem garantia sobre a eficácia e por utilizar uma técnica que se passava de braço em braço, contribuiriam para disseminação da sífilis (Rio de Janeiro, 2006; Porto; Ângela, Ponte, 2003).

No ano de 1904, quando a capital federal, foi assolada pela epidemia de varíola, Oswaldo Cruz apresentou ao Congresso Nacional um projeto de lei- onde a população deveria ser obrigada a se vacinar e a se revacinar contra a doença, além de incluir multas aos indivíduos que se recusassem a aceitar esta medida, exigir atestado de vacinação, como por exemplo, para a realização de matrículas em escolas, casamentos e viagens, e permitir que os vacinadores adentrassem nas residências da população a força para a realização da vacinação (Iyda, 1994; Hochman, 2011).

Tal lei teve repercussões nunca antes vivenciadas, onde a população, já insatisfeita com o governo, se opôs a mesma, sendo instaurado um movimento social denominado Revolta da Vacina, onde diversas pessoas foram presas e até mesmo deportadas (Hochman, 2011).

Sendo assim, este estudo tem como objeto de pesquisa a Revolta da Vacina na capa da
Revista da Semana como assinatura imagética de implantação de uma política nacional de saúde. Para operacionalizar o estudo traçou como objetivo analisar os elementos simbólicos na capa da Revista da Semana de 1904 sobre a Revolta da Vacina como meio de leitura imagética de um movimento social e sanitário.

\section{METODOLOGIA}

Trata-se de uma pesquisa documental (Lima, 2011), com abordagem préiconográfica e iconográfica (Panofsky, 1986), que teve por estratégia demonstrar o uso da análise histórico-semiótico (Andrade, 1990) em uma imagem publicada na capa da Revista da Semana.

A Revista da Semana surgiu no início do século XX no contexto da modernização da cidade do Rio de Janeiro, então capital federal. A justificativa desta revista como fonte de pesquisa se baseia na análise imagética que se apoia no sentido dela ser a pioneira na publicação de fotografias e desenhos. Mesmo tendendo buscando um perfil eclético, com o objetivo de conquistar leitores de todas as tendências, a Revista da Semana também tomou partido no contexto político de sua época (Sodré, 1999).

A busca e a coleta da imagem foram feitas a partir de pesquisa no acervo do Arquivo Nacional localizado no Rio de Janeiro, onde foi selecionada a edição n. ${ }^{\circ} 229$ de 02 de outubro de 1904 da capa da Revista da Semana onde retratava sobre questões de vacinação.

Para analisar a representação pictórica da Revolta da Vacina na capa da Revista da Semana, entendeu-se como parâmetro as primeiras fases de análise das noções de Erwin Panofsky, pré-iconográfica e iconográfica.

Na pré-iconográfica, têm-se as descrições 
das formas, cores e volumes em que se dá o objeto retratado na imagem e requer para sua leitura vivências práticas possíveis a qualquer pessoa, porém quando essas experiências não propiciam uma leitura fidedigna, torna-se necessário ampliá-las por meio de pesquisas em livros, artigos e em outras fontes de informação (Panofsky, 1986).

Já na iconografia, Panofsky (1986) relata que a imagem demanda conhecimentos que perpassa as experiências, exigindo uma proximidade com fontes literárias, porém estas, não asseguram a veracidade da análise e nem responde as lacunas que mantem-se indecifráveis ou vagos após a leitura, por isso, é necessário recorrer ao uso de outras imagens a fim de garantir a exatidão do que está sendo analisado.

No intuito de operacionalizar a análise, foi articulado conteúdos escritos para contextualizar o repertório da época, publicações acerca da temática e imagens que corroborem para o entendimento da mensagem que a imagem propõe passar às pessoas que a observam.

Os aspectos éticos da pesquisa referentes aos documentos imagéticos analisados respeitaram o que se refere a Lei número 9.610/1998 quanto a autorização, atualização e consolidação da legislação sobre direitos autorais e outras providências (Brasil, 1998).

\section{DESARROLLO DEL TEMA}

\section{A Revolta da Vacina na capital do Brasil pela perspectiva pré- iconográfica iconográfica}

No período colonial havia várias doenças transmissíveis, como a tuberculose, varíola, hanseníase, febre amarela, cólera; sendo que algumas levavam à morte de milhares de pessoas (Rouquayrol; Filho, Almeida, N. 2003; Sevcenko, 1993; Benchimol, 1990). Perante essa situação sanitária, eram tomadas algumas medidas de saneamento e urbanização, com vistas a diminuir o impacto desses agravos nos centros de maior interesse comercial, de forma a incentivar a vinda de trabalhadores estrangeiros ao país, para que não prejudicasse a produção e a comercialização internacional (Costa, 1985).

No início do século XX, o Rio de Janeiro era a capital do país e passava por graves problemas sociais, devido ao seu crescimento acelerado e desordenado. Era uma cidade com aproximadamente $700 \mathrm{mil}$ habitantes com um elevado grau de pobreza, e apresentava um perfil demográfico caótico em diversos aspectos, como problemas urbanos e sanitários descritos pelas habitações insalubres e populosas, conhecidas como cortiços e em condições precárias de moradia, rede de esgoto e água insuficiente e toneladas de lixo espalhados pelas ruas (Rio de Janeiro, 2006; Sevcenko, 1993; Benchimol, 1990).

Na imagem abaixo, a Revista da Semana de 2 de outubro de 1904 trazia em sua capa, uma manchete sobre a Vaccina Obrigatória e retratava esse momento histórico por meio de dois personagens: o congresso e o povo. Referente a este, pode-se observar pelo recorte, as características físicas desse segmento social.

\section{FIGURA N. 01: Capa da Revista da Semana e} recorte da população

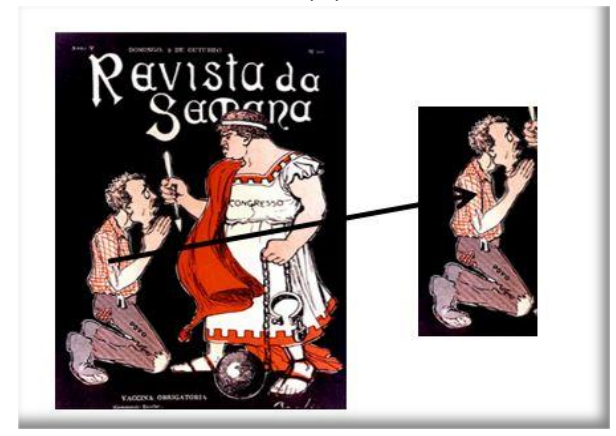

FONTE: Capa da Revista da Semana, 1904 
A população representada por um homem, do lado esquerdo da imagem, vestindo uma camisa quadriculada, com linhas vermelhas horizontais e verticais, rasgada na altura da manga, uma calça na cor marrom, bolso costurado com um tecido similar ao da camisa, na lateral da perna, escrita a palavra "POVO" e um rasgo, na altura do joelho. Seu sapato cinza, furado correspondente ao pé direito, deixa a mostra os dedos. A magreza aparente pelos traços delgados do rosto, evidenciado pela proeminência dos ossos e corpo franzino, poderia se inferir a tradução das más condições alimentares e, em geral, de pobreza pela qual vivia a maior parte da população.

No contexto político e social no qual a cidade encontrava-se, com as características do período colonial: suja, antiga e insalubre, ou seja, situação de pobreza desta população como retratado na imagem em análise. Para tanto, o então prefeito Pereira Passos, resolveu fazer uma reforma urbana, conhecida como "bota-abaixo". Tal remodelação urbanística visava transformar a cidade em uma metrópole moderna, seguindo o modelo de urbanização dos grandes centros comerciais europeus e dos Estados Unidos (Porto, Mayla, 2003; Benchimol, 1990). Portanto, ao se pensar na representação pictórica que esta imagem traz no recorte para o povo, há de se inferir que a condição de submissão e necessidade que se tinha com mais uma ação impositiva do governo, iria causar uma manifestação do povo e movimento de revolta -a Revolta da Vacina.

Outra perspectiva de análise pode ser feita por meio do recorte da Figura N. 02. O povo tem está com uma feição assustada, olhos arregalados, impetrante e boquiaberto. As mãos juntas na altura do queixo e as pernas dobradas, rente ao chão, condiz a um sinal de súplica.
FIGURA N. 02: Recortes do rosto, mãos e pernas do povo

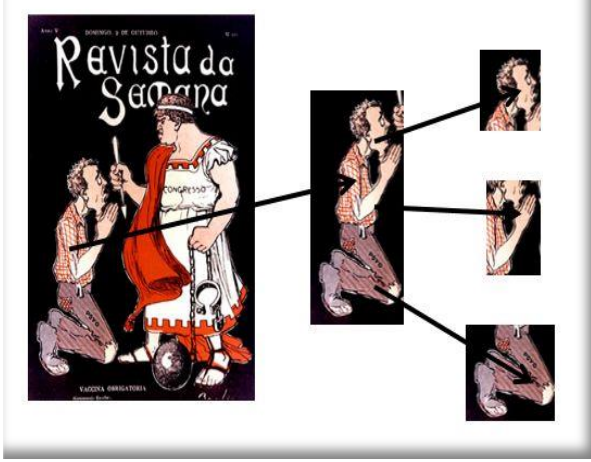

FONTE: Capa da Revista da Semana, 1904

A providência decretada pelo presidente para o controle das epidemias foram campanhas sanitárias, as quais ficaram sob responsabilidade de Oswaldo Cruz, diretor do Serviço de Saúde Pública, que implementou estratégias inovadoras para combater as doenças, tais como as Brigadas Mata-Mosquitos, aos quais tinham autoridade para invadir a casa das pessoas e até mesmo derrubá-las caso fossem consideradas uma ameaça à saúde pública. Para matar os ratos, vetores da peste bubônica, mandou espalhar raticida pela cidade e tornou obrigatório o recolhimento do lixo pela população (Rio de Janeiro, 2006; Sevcenko, 1993).

Ademais, Oswaldo Cruz elaborou o Projeto de Lei que propunha a vacinação obrigatória contra a varíola, visto que a cidade estava assolada por uma epidemia ocasionada por essa doença. A par da relutância da opinião pública a respeito da vacinação, preparou uma campanha de vacinação nos moldes militares, criando uma polícia sanitária que tinha autoridade para adentrar nas casas para desinfetá-las e vacinar as pessoas à força. (Sevcenko, 1993; Benchimol, 1990; Hochman, 2011; Porto, Mayla, 2003).

Ao lado direito e em pé, a figura simboliza o congresso, este retratado por um homem 
de aparência forte, hostil e truculenta, que olha de forma austera para o povo. Sua vestimenta composta por túnica, toga e calcei, se assemelha aos trajes usados na Roma Antiga por grupos sociais mais favorecidos e possibilitava identificar o status social. A cor e o tamanho diferenciavam as condições de prestígio e sua função na sociedade. Os mais desfavorecidos, como escravos, plebeus e até mesmo soldados, costumavam usar apenas uma túnica simples (Mattingly, 2011).

FIGURA N. 03. Recorte do congresso

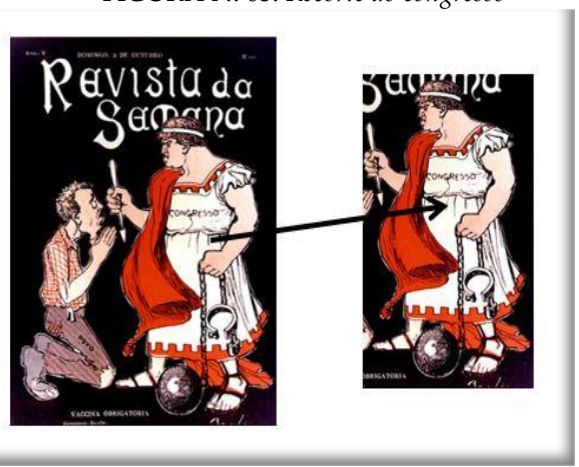

FonTE: Capa da Revista da Semana, 1904

No meio do peito, tem- se a palavra "CONGRESSO". Sua mão esquerda traz um grilhão, algemas usadas para os pés; na outra mão, segura de forma firme e próximo ao rosto do povo, uma lança.

FIGURA N. 04. Equiparação entre a coroa de flores usada na Roma Antiga e a faixa do Congresso

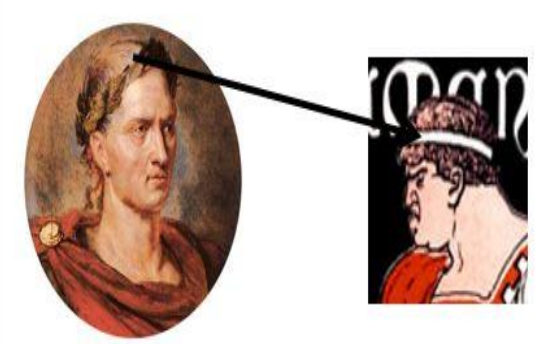

FONTE: Peter Paul Rubens/Capa da Revista da Semana, 1904
A faixa na cabeça do congresso se assemelha a coroa de folhas usada na Roma Antiga como um símbolo de vitória e conquista (Rubio, 2001). Tal representação exprime o poder do governo que no período da Primeira República possuía características conservadoras e autoritárias, mantendo a população dominada e subordinada as suas ordens.

FIGURA N. 05. Recorte da lanceta e equiparação com a seringa

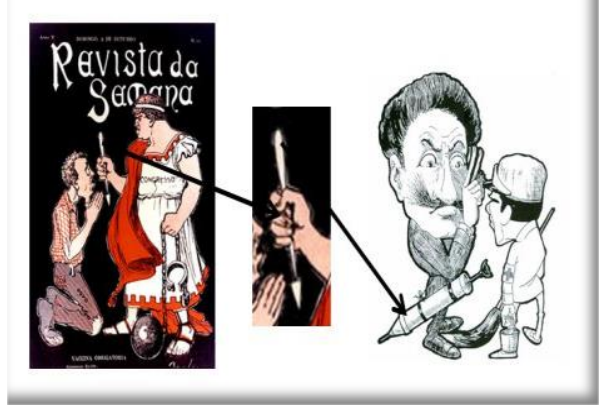

FONTE: Capa da Revista da Semana, 1904/Charge de J. Carlos, Na hygiene dando ordens, 1904

A injeção era aplicada por uma agulha bifurcada ou com uma pistola injetora, no deltóide direito. Tal prática era dolorosa, o que aumentava ainda mais a rejeição e insatisfação da população que já se encontrava descontente com a violência da polícia sanitária e temerosa sobre os supostos perigos da vacina, uma vez que não havia esclarecimentos suficientes para a população a respeito desse imunobiológico (Sevencko, 1993; Hockman, 2011). A lanceta como representação abstrata da seringa pode relacionar-se ao fato de que na Roma Antiga era um instrumento usado para coagir e atacar os adversários de guerra (Mattingly, 2011). Tendo em vista todo esse contexto, tal representação pode significar o poder do governo de Rodrigues Alves e sua autoridade sobre a população oprimida, como uma possível simbologia do poder onipotente do Congresso. 
Outro elemento na análise do Congresso é o grilhão segurado pelo personagem que referencia o governo. Grilhão é uma corrente de metal pesado, utilizado no período colonial para o transporte de escravos, no intuito de que eles não fugissem e nem se mexessem muito. $\mathrm{O}$ objeto se assemelha a uma algema e virou símbolo de opressão e crueldade (Goulart, 1971).

FIGURA N. 06. Recorte do grilhão

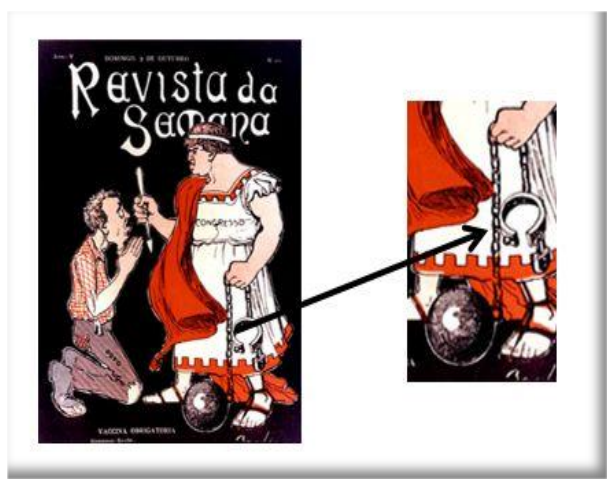

FONTE: Capa da Revista da Semana, 1904

A Somando à característica da presidência de Rodrigues Alves ao contexto históricopolítico e o significado do grilhão, é possível inferir que há uma relação de poder do Estado sobre a população, estando esta sujeita à autoridade e repressão do governo, o qual ocasionou o descontentamento da população que já havia sofrido com a Reforma Urbana, resultando em protestos populares contra as desapropriações, demolições e do novo código de posturas municipais que proibiam atividades rotineiras do povo, como a criação de porcos nos quintais e a venda de miúdos nas ruas da cidade (Sevcenko, 1993; Hochman, 2011; Rio de Janeiro, 2006). A população diante deste cenário se impôs, demonstrando sua indignação e indo as ruas enfrentar tal austeridade (Sevenko, 1993; Rio de Janeiro, 2006). Um exemplo disto se dá pela representatividade por parte da população ao visualizar-se a charge de Leonidas publicada na revista O Malho em 1904 (Figura N. 07).

A população lutou contra a vacinação obrigatória imposta pelo governo nas ruas da cidade do Rio de Janeiro, sendo representada pela diversidade das pessoas e os utensílios improvisados como armas. De um lado, havia as forças do governo querendo conter a população com tiros e avanço da cavalaria, utilizando equipamentos e armas adequadas, e do outro lado tinha a população munida com utensílios domésticos, pedras e destroços da reforma da cidade.

\section{FIGURA N. 07. Representação da população frente as tropas do governo}

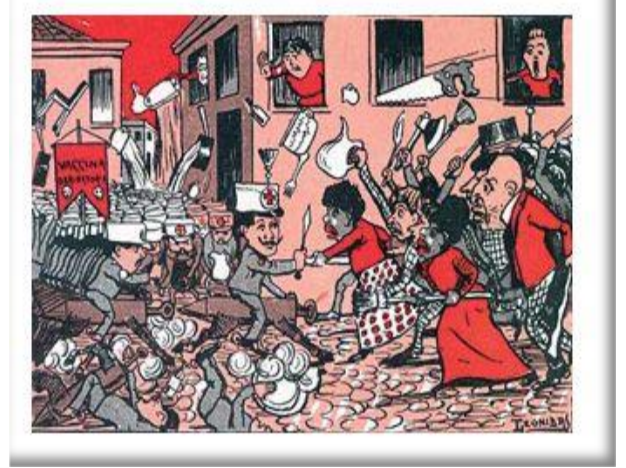

FONTE: Charge de Leonidas, revista O Malho, 1904

No dia 10 de novembro de 1904, após a publicação da regulamentação da vacinação obrigatória, espaços como a Rua do Ouvidor, Praça Tiradentes e Largo de São Francisco de Paula foram tomados pela população. Tal afronta não passou despercebida pelas autoridades, que designaram a polícia para proibir e dispersar quaisquer reuniões públicas, além de prender os oradores. Porém a população não aceitou o fato e revidou com pedradas sobre a polícia (Sevcenko, 1993; Rio de Janeiro, 2006). 
O enfrentamento entre população e polícia durou seis dias (10-16 de novembro), entretanto, no dia 16 de novembro de 1904, frente às perdas de ambos os lados e o caos que a cidade se tornou, Rodrigues Alves revoga a lei da obrigatoriedade da vacinação. A decisão foi $o$ fator determinante para o término desse conflito, se extinguindo tão rapidamente quanto sua ascensão (Sevcenko, 1993). A Revolta da Vacina é considerada um dos maiores levantes populares ocorridos no Brasil no século XX (Chalhoub, 1996), mas mais do que isso, ela deve ser tratada como um momento de grande importância para todos os trabalhadores de saúde pública, pois é preciso que haja a compreensão dos mesmos de que a vacinação é um campo de difícil entendimento da população, se tornando um fenômeno de grande complexidade, pois se associa a crenças e concepções políticas, científicas e culturais de cada indivíduo (Brasil, 2010).

A vacinação não deve ser apenas um parâmetro para a medicina ou as ciências biomédicas, ela também deve ser entendida como resultante de processos históricos, onde está sujeita a múltiplas interações, respeitando o direito coletivo e individual, as relações entre Estado, sociedade, indivíduos, empresas e países, a informação, a ética e a vida e a morte (Brasil, 2010). Sendo assim, na análise imagética consegue-se entender que as relações entre o povo e o governo se mostravam com objetivos distintos por carência de negociação e discussão entre as partes, meio pelo qual poderia se construir de forma coletiva, uma política de saúde que atualmente se encontra estabelecida. Todavia, há de se considerar que o conflito Revolta da Vacina foi produto, e também semente, de uma ação de prevenção de agravos que mudou a história a saúde pública do país.

\section{CONSIDERAÇÕES FINAIS}

Com esse estudo, foi possível fazer um aprofundamento acerca de dois personagens que são representantes opostos dentro de uma sociedade marcada por determinantes, disparidades sociais e com políticas que não favoreciam a realidade econômica e sanitária vivenciada; e também retratava a relação de poder vigente na época em que foram implementadas medidas que culminaram no movimento da Revolta da Vacina. Entender este movimento político e social que aconteceu no período da Primeira República se faz necessário para compreender a evolução dos imunobiológicos, desde sua inserção como medida de prevenção de doenças transmissíveis, até perceber os avanços alcançados na redução da morbimortalidade em todo o país e no mundo.

Apesar disso, é possível identificar o resquício da Revolta da Vacina em diversos movimentos sociais pelo mundo nos dias atuais, a destacar o continente europeu. A disseminação de informações e inclusive pesquisas que corroboram para não vacinação, promovem contágios de doenças que deveriam estar erradicadas, como por exemplo, sarampo e poliomielite. Estas manifestações políticas e populares agregam valores na construção de uma política pública de saúde, através da participação da população, com a qual se impulsiona e constrói a ampliação das linhas de cuidado e de enfretamentos aos determinantes sociais.

Isto significa que analisar a Revolta da Vacina pela capa da Revista da Semana permite compreender as modificações, construções e pesquisas que são formuladas a cerca da vacinação como cuidado em saúde, entendendo como um documento imagético pode possibilitar uma viagem ao passado que proporciona entender os 
conflitos contemporâneos para aplicação de imunobiológicos como construção do conhecimento.

\section{REFERÊNCIAS}

- Andrade, A.M.M.S. (1990). Sob o signo da imagem: A produção da fotografia e o controle dos códigos de representação social da classe dominante do Rio de Janeiro, na primeira metade do século XX. (Tese de Mestrado). Niterói: Faculdade de História da Universidade Federal Fluminense:. Recuperado de http://www.labhoi.uff.br/sites/default/files/dssam.p df.

- Benchimol, J.L. (1990). Pereira Passos: um Haussmann tropical. Rio de Janeiro: Secretaria Municipal de Cultura.

- Bluteau, R. (1712) Vocabulário portuguez e latino. Coimbra.

- Brasil. Lei 9.610, de 19 de Fevereiro de 1998. Altera, atualiza e consolida a legislação sobre direitos autorais e dá outras providências. Diário Oficial da União, Brasília, 20 fev. 1998.

- Brasil. Ministério da Saúde (2010). Na corda bamba de sombrinha: a saúde no fio da história.

- Chalhoub, S. (1996). Cidade febril: cortiços e epidemias na corte imperial. São Paulo: Companhia das Letras.

- Costa, N.R. (1985). Lutas urbanas e controle sanitário: origens, das políticas de saúde no Brasil. Petrópolis, Rio de Janeiro: Vozes Abrasco.

- Iyda, M. (1994). Cem anos de saúde pública: a cidadania negada. São Paulo: Universidade Estadual Paulista.

- Goulart, J.A. (1971). Da palmatória ao patíbulo (Castigo de escravos no Brasil). Rio de Janeiro: Conquista.

- Hochman, G. (2011). Vacinação, varíola e uma cultura da imunização no Brasil. Ciênc. Saúde Coletiva, 16 (2), 2011. Recuperado de http://www.scielo.br/scielo.php?script=sci arttext\&p $\mathrm{id}=$ S1413-81232011000200002.

- Lima, D.V.M. (2011) Desenhos de Pesquisa: Uma contribuição para autores. Online Brazilian Journal of Nursing, 10 (2). Recuperado de http://www.objnursing.uff.br/index.php/nursing/arti cle/view/3648.

- Mattingly, D. (2011). Imperialism, power, and identity. Experiencing the Roman Empire. Princeton: Princeton University Press.

- Oliveira, E.C.A. (2013). Epidemia de varíola e o medo da vacina em Goiás. História, Ciências, Saúde, 20 (3),
939-962. Recuperado de http://www.scielo.br/pdf/hcsm/v20n3/0104-5970hcsm-20-03-0939.pdf.

- Panofsky, E. (1986). "Iconografia e Iconologia: Uma introdução ao estudo da arte da Renascença". In: Significado nas Artes Visuais. Tradução: Maria Clara F. Kneese e J. Guinsburg. São Paulo: Perspectiva.

- Porto, Angela. e Ponte, C.F. (2003). Vacinas e campanhas: imagens de uma história a ser contada. História, Ciências, Saúde, 10 (suplemento 2), 725-742. Recuperado de http://www.scielo.br/pdf/hcsm/v10s2/a13v10s2.pdf.

- Porto, Mayla Y. (2003). Uma revolta popular contra a vacinação. Cienc. Cult, 55 (1),53-54. Recuperado de http://cienciaecultura.bvs.br/scielo.php?pid=S0009$\underline{67252003000100032 \& \text { script=sci_arttext\&tlng. }}$.

- Rio de Janeiro (2006). 1904 -Revolta da Vacina. A maior batalha do Rio.

- Rouquayrol, M.Z e Filho, N.A (2003). Epidemiologia \& Saúde. Rio de Janeiro: Medsi.

- Rubio, K. (2001). O imaginário esportivo contemporâneo: o atleta e o mito do herói. São Paulo: Casa do psicólogo.

- Sevcenko, N. (1993). A Revolta da vacina: Mentes insanas em corpos rebeldes. São Paulo: Scipione.

- Sodré, N.W. (1999). História da Imprensa no Brasil. Rio de Janeiro: Mauad. 